\title{
Mismatch between school furniture and anthropometric measures among primary school children in Mersing, Johor, Malaysia
}

\begin{abstract}
This study is a cross-sectional study with the objective to determine mismatch between school furniture and anthropometric measurement among primary school children in Mersing. The sample consisted of 91 primary school children (46 male and 45 female) from Year 2 and Year 5 in two schools in Mersing District, Malaysia. Seven anthropometric measurement (height, weight, popliteal height, buttock-popliteal length, hip breadth, shoulder height and elbow height while sitting) as well as 5 furniture dimensions (seat height, seat depth, seat width, backrest height and seat to desk height) were taken. Instruments used were Martyn type anthropometer set, ruler, height scale and weighing scale. Differences between genders in anthropometric measurements were also investigated in this study. Findings showed $100 \%$ high mismatch for seat height, seat depth, desk height respectively while $56 \%$ match and only 44\% mismatch for backrest height among Year 2 children. Year 5 students reported contrary result with $79 \%$ mismatch for seat height, $91 \%$ for backrest height and $100 \%$ for both seat depth and desk height. There was no significant difference between genders for both age groups. In conclusion, there was a mismatch between furniture and children's anthropometric measurements. It is recommended that school furniture be redesigned so as to conform to the children's physiological measurement. The use of adjustable furniture can be taken into consideration in designing new furniture for school environments in order to meet all the differences in children anthropometry.
\end{abstract}

Keyword: Mismatch; Anthropometric data; School furniture; Primary school children 